\title{
Disparity between cigarette and smokeless tobacco taxation among various WHO FCTC Parties
}

\author{
Shivashankar Kengadaran' ${ }^{1}$ Divvi Anusha ${ }^{1}$
}

\begin{abstract}
INTRODUction Tobacco taxation is the most effective way to prevent and reduce tobacco use. However, all tobacco products are not taxed in the same manner or same rate across countries. Hence, this study aimed to identify the total tobacco tax disparity among countries that are Parties to the WHO FCTC agreement. METHODS A cross-sectional study was conducted among the signees of the World Health Organization (WHO) Framework Convention on Tobacco Control (FCTC) treaty. The trends of taxation on cigarettes and smokeless tobacco products were retrieved from WHO FCTC reports published in 2017 and 2018; median tax percentages were then compared based on the economic status of the countries and their corresponding WHO region. Data were analyzed using SPSS version 21.0. A p-value $<0.05$ was considered statistically significant.

RESULTS Maximum disparity between cigarette and smokeless tobacco taxation was observed in the South-East Asia region, followed by the Eastern Mediterranean, Western Pacific, and African regions. The disparity was comparatively less in the region of the Americas and the European region $(\mathrm{p}<0.05)$.

CONCLUSION There was variation in tobacco taxation among various FCTC Parties according to the economic status and WHO region of each country.
\end{abstract}

AFFILIATION

1 Department of Public Health Dentistry, Indira Gandhi Institute of Dental Sciences, Sri Balaji Vidyapeeth, Pondicherry, India

\section{CORRESPONDENCE TO}

Shivashankar Kengadaran. Department of Public Health Dentistry, Indira Gandhi Institute of Dental Sciences, Sri Balaji Vidyapeeth, 607402, Pondicherry, India. E-mail: shiva.freee@gmail.com ORCID ID: https://orcid.org/00000002-6868-9639

\section{KEYWORDS}

taxation, disparity, smokeless tobacco, cigarettes

Received: 20 May 2020

Revised: 26 July 2020

Accepted: 9 October 2020

\section{INTRODUCTION}

Globally, tobacco use is the leading cause of preventable death. Worldwide, the number of youth aged 13-15 years who smoke cigarettes is estimated to be about 25 million, with almost 13 million using smokeless tobacco products ${ }^{1}$. Tobacco-related illnesses and premature mortality devastate the economies of nations because of sickness and death within the workforce. This scenario is severe, particularly among highly populated low- and middle-income countries, as tobacco use is high in those areas ${ }^{2}$.

Tobacco taxation is the most effective way to prevent and reduce tobacco use. A sufficiently large tax increase will raise tobacco product prices, making tobacco products less affordable, driving down their consumption among those who continue to use them ${ }^{3}$. Further, the revenue generated through taxation can provide much needed funding for tobacco control programs. However, all the tobacco products are not taxed in the same manner or same rate $^{4}$. Tobacco tax parity refers to the idea that taxes on smokeless tobacco products should be increased to be on par with the tax rates imposed on cigarettes so that countries do not lose their revenues when smokers switch from cigarettes to other cheaper tobacco products.

Several countries enforce differential taxes based on the characteristics of cigarettes and other tobacco products. Previously, the United Kingdom imposed differential taxes on cigarettes based on tar and nicotine content. However, this differential taxation may be prone to tax avoidance ${ }^{5}$. The tobacco industry might alter an attribute of a brand, such as retail price, that consequently reclassifies the brand into a lower tax bracket. This phenomenon was observed in Egypt, where an international brand dropped its 
price just enough to be reclassified into a lower tax bracket ${ }^{5,6}$.

Historically, smokeless tobacco products have been taxed at much lower rates than cigarettes, even though they are essentially the same thing and their use carries similar health risks. Many jurisdictions are in the process of modernizing their tobacco tax statutes, to ensure that smokeless tobacco products are not under-taxed ${ }^{7,8}$. The underlying concern is that, in the face of rising cigarette excise taxes, smokers may turn to lower priced alternatives (smokeless tobacco products) rather than quit ${ }^{9}$. Thus, tax increases need to be applied symmetrically across all types of tobacco products in a manner that equalizes their retail price, so that consumers will not turn away from relatively high-priced products towards those with lower prices.

Little information and updates on smokeless tobacco indicators are available from the World Health Organization (WHO) Framework Convention on Tobacco Control (FCTC) Convention Secretariat's Global Progress Report on implementation of the FCTC, WHO Report on the Global Tobacco Epidemic, and the WHO FCTC Global Knowledge Hub on Smokeless Tobacco. Moreover, information on smokeless tobacco control measures is inadequate or not available from several countries. Hence, this study aimed to identify the total tobacco tax disparity among countries that are Parties to the WHO FCTC agreement.

\section{METHODS}

A cross-sectional study was conducted among the signees of the World Health Organization Framework Convention on Tobacco Control treaty. Secondary or published data regarding the country profile, taxation on smokeless tobacco (SLT) products and cigarettes were drawn from different sources such as the Global WHO FCTC Implementation progress reports 2017 and $2018^{10}$, WHO reports on the global tobacco epidemic $2019^{11}$ and additionally tobacco control legislation and regulations that were available in English. The trends of taxation on cigarettes and smokeless tobacco products were retrieved from the abovementioned sources. The compiled data were entered in Microsoft Excel spreadsheet and analyzed using Statistical Package for Social Sciences (SPSS) software version 21.0. The median tax percentages were then compared based on the economic status and WHO regions of the countries, using the nonparametric Kruskal Wallis test. A p-value $<0.05$ was considered significant statistically and adjusted pairwise comparison was done for the significant variables.

\section{RESULTS}

The results show that taxes were higher on cigarettes than smokeless tobacco products among all the FCTC Parties classified by income. However, this difference was statistically significant only among low income, lower middle-income, and upper middle-income countries $(\mathrm{p}<0.001)$ (Figure 1). Similarly, taxes on cigarettes were higher compared to smokeless tobacco products in all the FCTC Parties classified by WHO regions. This difference was statistically significant in the South-East Asia region $(\mathrm{p}<0.001)$, Eastern Mediterranean $(p=0.043)$, Western Pacific $(p=0.038)$, and African regions $(\mathrm{p}<0.001)$ (Figure 2$)$.

We analyzed the difference in cigarette taxation between various FCTC Parties based on their economic status. It was found that the median tax percentage on cigarettes was maximum among highincome countries (71.8), followed by upper middleincome (54.1), lower middle-income (41.2), and low-income countries (36.75). This difference was found to be statistically significant $(\mathrm{p}<0.001)$ (Table $1)$. The pairwise comparison shows a statistically significant difference in cigarette taxation between low income and upper middle-income countries; low-income and high-income countries, and lower middle-income and high-income countries $(\mathrm{p}<0.05)$ (Figure 3).

It was found that the median tax percentage on smokeless tobacco products was highest among high-income countries (69.0) followed by upper middle-income countries (41.8), lower middleincome countries (21.1), and least among lowincome countries $(7.9)(p<0.001)$ (Table 1). The pairwise comparison of the same shows a significant difference in smokeless tobacco taxation between low-income and high-income countries and lower middle-income and high-income countries $(\mathrm{p}<0.05)$ (Figure 4).

Comparison based on the WHO region revealed that the median tax percentage for cigarettes was significantly higher for the European region (73.8) 
Figure 1. Comparison of tobacco taxation between cigarettes and other tobacco products across FCTC Parties based on their economic status

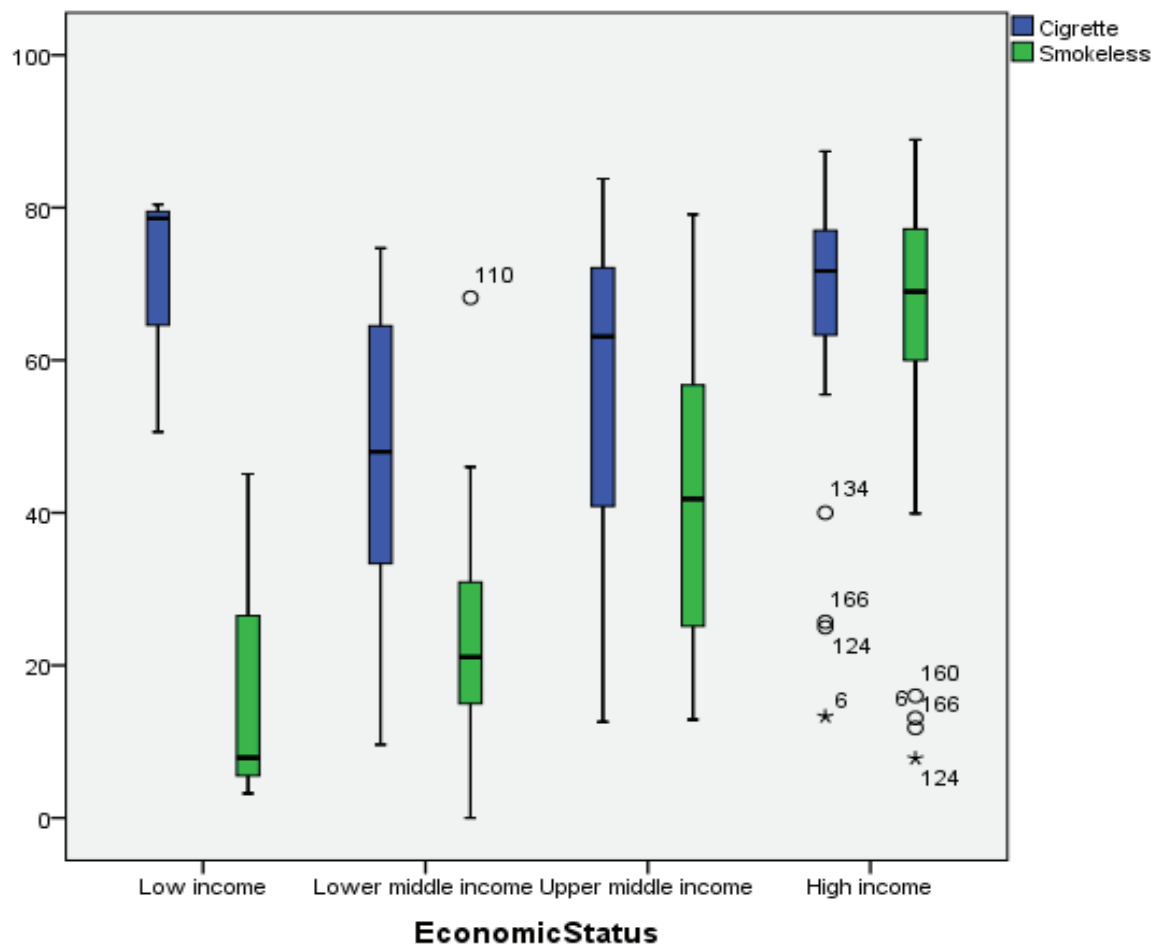

Box plots of median tax percentages for cigarettes (blue color) and smokeless tobacco products (green color) across FCTC Parties based on their economic status. The median tax percentage is shown by the line that divides the box into two parts. The upper and lower whiskers represent scores outside the middle $50 \%$. Data outside the whiskers are outliers.

Figure 2. Comparison between cigarette and smokeless tobacco taxation among FCTC Parties in WHO regions

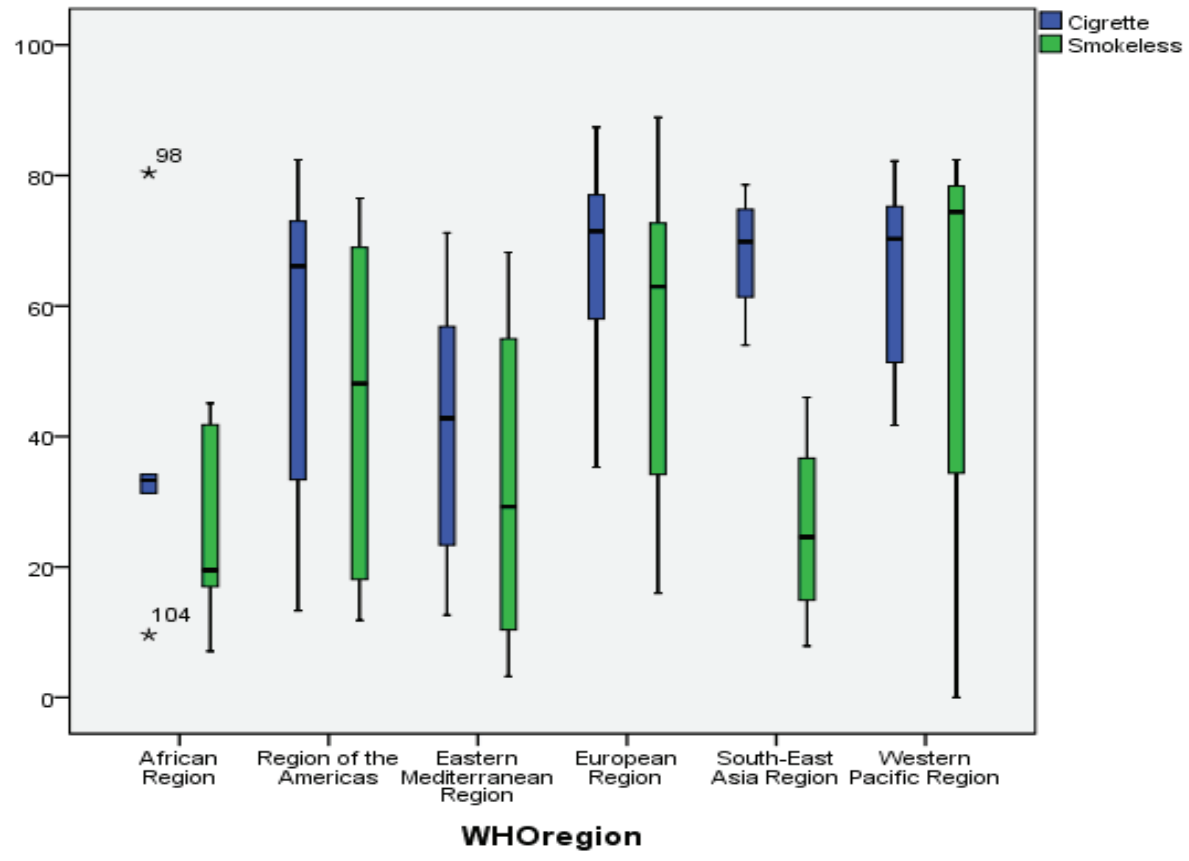

Box plots of median tax percentages for cigarettes (blue color) and smokeless tobacco products (green color) across FCTC Parties based on WHO regions. The median tax percentage is shown by the line that divides the box into two parts. The upper and lower whiskers represent scores outside the middle 50\%. Data outside the whiskers are outliers. 
Table 1. Difference in cigarette and smokeless tobacco taxation between the countries based on their economic status

\begin{tabular}{llrrr} 
Tax & Economic status & N & $\begin{array}{c}\text { Median } \\
\text { tax \% }\end{array}$ & $p$ \\
\hline \multirow{2}{*}{ Cigarette } & Low income & 24 & 36.8 & \\
& Lower middle-income & 43 & 41.2 & $<0.001$ \\
& Upper middle-income & 57 & 54.1 & \\
\cline { 2 - 4 } Other & High income & 53 & 71.8 & \\
tobacco & Low income & 3 & 7.9 & \\
products & Lower middle-income & 12 & 21.1 & \\
& Upper middle-income & 23 & 41.8 & $<0.001$ \\
& High income & 25 & 69.0 &
\end{tabular}

Figure 3. Pairwise comparison of cigarette taxation among FCTC Parties based on economic status

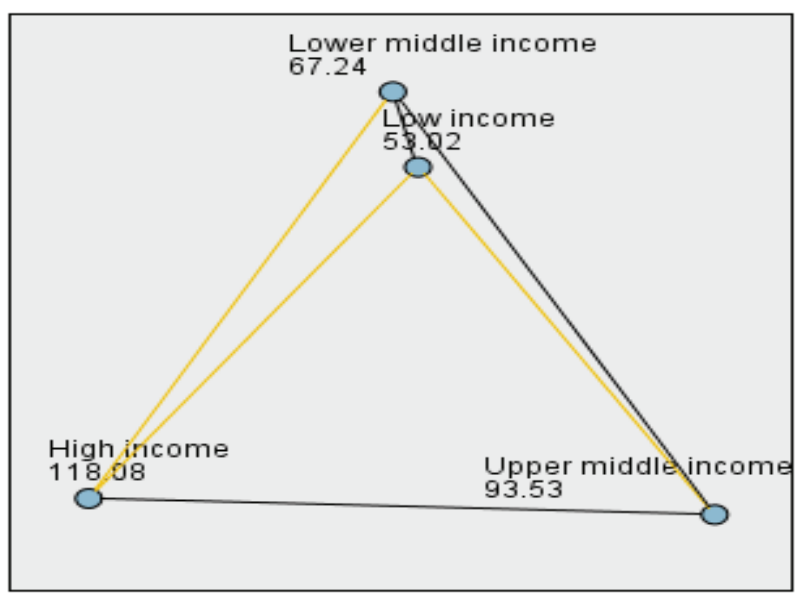

Each node depicts median tax percentage of cigarettes among FCTC Parties based on economic status. The yellow line represents the difference in the median tax percentage among FCTC Parties that was statistically significant. The black line shows that the difference was not significant.

followed by South-East Asia (63.25), Eastern Mediterranean (56.4), Western Pacific (54.15), the Americas (49), and African regions (37.3) $(\mathrm{p}<0.001)$ (Table 2). Pairwise comparison of cigarette taxation based on WHO regions shows a statistically significant difference in cigarette taxation between the African and European regions, Eastern Mediterranean and European regions, and region of the Americas and European region $(\mathrm{p}<0.05)$ (Figure $5)$.

It was found that median tax percentage on smokeless tobacco products was maximum in the Western Pacific region (74.4), followed by the European (62.95), the Americas (48.1), Eastern
Figure 4. Pairwise comparison of taxation on other tobacco products among FCTC Parties based on economic status

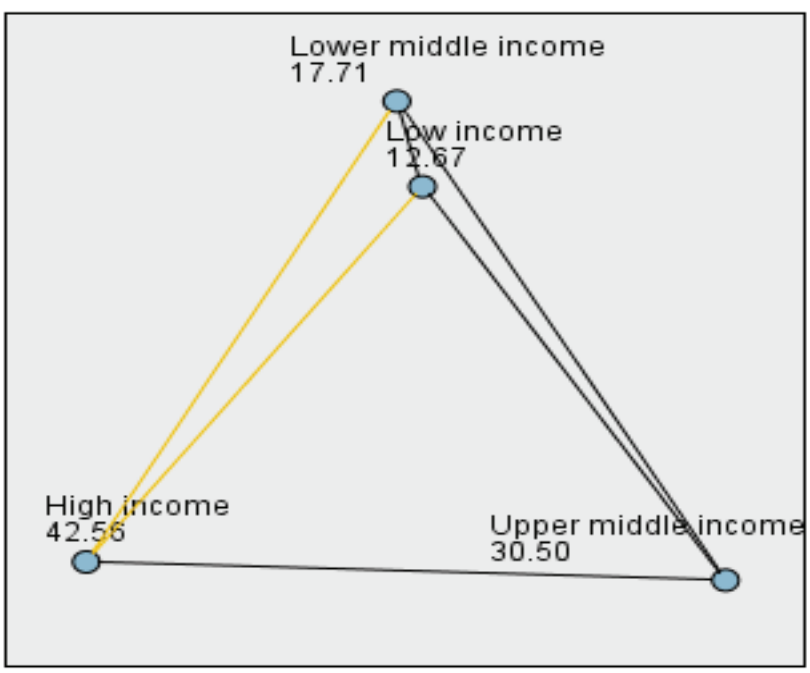

Each node depicts median tax percentage of other tobacco products among FCTC Parties based on economic status. The yellow line represents the difference in the median tax percentage among FCTC Parties that was statistically significant. The black line shows that the difference was not significant.

Table 2. Difference in cigarette and smokeless tobacco taxation between various WHO regions

$\begin{array}{llrrrr}\text { Tax } & \text { WHO region } & \text { N } & \begin{array}{c}\text { Median } \\ \text { tax \% }\end{array} & p \\ \text { Cigarette } & \text { African Region } & 43 & 37.3 & \\ & \text { Region of the Americas } & 32 & 49.0 & \\ & \text { Eastern Mediterranean } & 19 & 56.4 & \\ & \text { Region } & & & <0.001 \\ & \text { European Region } & 49 & 73.8 & \\ & \text { South-East Asia Region } & 10 & 62.4 & \\ \text { Other } & \text { Western Pacific Region } & 24 & 54.2 & \\ \text { tobacco } & \text { African Region } & 5 & 19.5 & \\ \text { products } & \text { Region of the Americas } & 13 & 48.1 & \\ & \text { Eastern Mediterranean } & 8 & 29.3 & \\ & \text { Region } & & & 0.034 \\ & \text { European Region } & 26 & 63.0 & \\ & \text { South-East Asia Region } & 4 & 24.6 & \\ & \text { Western Pacific Region } & 7 & 74.4 & \end{array}$

Mediterranean (29.25), South-East Asia (24.6), and African regions (19.5) $(\mathrm{p}=0.034)$ (Table 2). Pairwise comparison of smokeless tobacco taxation among FCTC signees shows no statistically significant differences based on WHO regions (Figure 6). Further details are given in the Supplementary file. 
Figure 5. Pairwise comparison of cigarette taxation among FCTC Parties in WHO regions

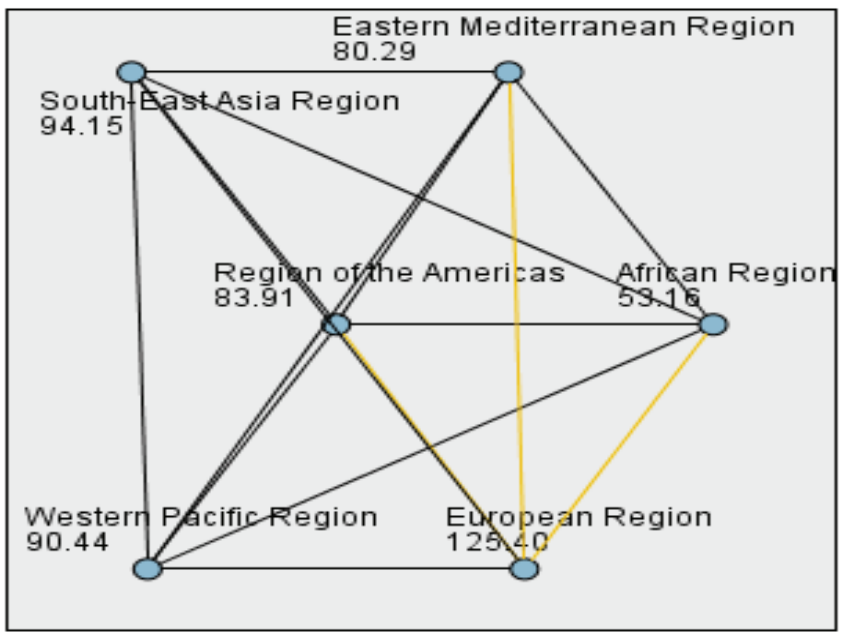

Each node depicts median tax percentage of cigarettes among FCTC Parties in WHO regions. The yellow line represents the difference in the median tax percentage among FCTC Parties that was statistically significant. The black line shows that the difference was not significant.

\section{DISCUSSION}

Parties' implementation of taxation on smokeless tobacco products lags in comparison to cigarettes. Additional attention toward smokeless tobacco is as important as taking continued measures against smoking. The fact that taxes for smokeless tobacco are way lower than those of cigarettes could be attributed to the relatively low cost of smokeless tobacco products. Lower taxes contribute to the increasing affordability of smokeless tobacco products ${ }^{12}$. Recently in many developed countries, a substantial number of price-conscious smokers of factory-made cigarettes (FM) are encouraged to self-assemble cigarettes by hand or roll-your-own tobacco (RYO) to reduce the cost of smoking ${ }^{13}$. Hence, increased taxation on other tobacco products (RYO and SLT) would address their relative affordability, especially if it resulted in comparable costs to other tobacco products or factorymade cigarettes.

Studies from low-income and lower middleincome countries reveal that with a significant increase in tax, the consumption of smokeless tobacco products is reduced ${ }^{14,15}$. Similarly, a study from four high-income countries also shows that consumers from the countries where tobacco taxes are higher (UK and Australia) reduced the amount of tobacco in their RYO cigarettes compared with
Figure 6. Pairwise comparison of taxation on other tobacco products among FCTC Parties in WHO regions

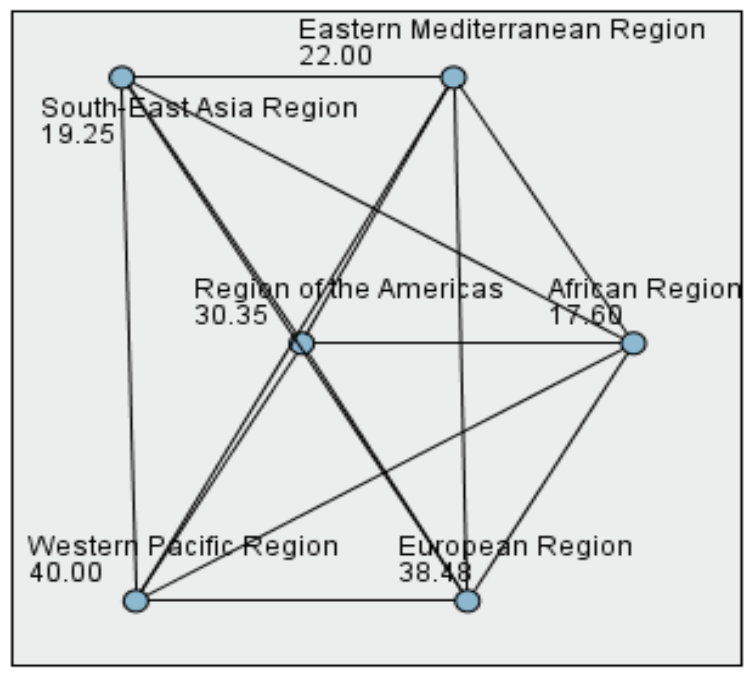

Each node depicts median tax percentage of other tobacco products among FCTC Parties in WHO regions. The yellow line represents the difference in the median tax percentage among FCTC Parties that was statistically significant. The black line shows that the difference was not significant.

those from USA and Canada where tobacco taxes are lower ${ }^{16}$.

Though the World Health Organization (WHO) recommends that tobacco taxes must account for at least $70 \%$ of the market price of tobacco products ${ }^{17}$, only 54 and 15 Parties had implemented the recommendation on cigarette and smokeless tobacco products, respectively. Simply put, taxation as a regulatory tool against smokeless tobacco use is highly underutilized among most Parties, even though the adoption of the taxation is highly feasible. Contrary to the assessment of the impact of tax increases in reducing cigarette demand, the documentation concerning the impact of increases in smokeless tobacco taxation is inadequate. Few studies have assessed the effectiveness of tax increases on the demand for tobacco products other than cigarettes ${ }^{14-16}$.

To discuss price equity and tax equity, we need to understand the concept in three different views. First, according to manufacturers of tobacco products, the manufacturing of cigarettes requires more time and resources compared to smokeless tobacco. Hence, the price of the products varies based on the investment in the manufacturing of the product ${ }^{18}$. Second, although there is no safe way to indulge in tobacco use, many economists 
find that smoking might have a greater impact on the population. Also, when it comes to smoking cigarettes there is always the risk of secondhand smoke to others who do not smoke, which in turn increases the government expenditure to treat smoking-related diseases ${ }^{19}$. Third, according to public health personnel, increasing taxes alone might lead to dual use or an increase in smokeless tobacco use in countries with a high prevalence of smoking. Hence, in those countries, it is important to emphasize price equity along with tax equity. On the other hand, in low-income countries and countries with high smokeless tobacco prevalence, tax equity would serve the purpose.

FCTC Article 6 advocates that any tax increase introduced for cigarettes should also be applied to smokeless tobacco products to avoid substitution ${ }^{20}$. Given that smokeless tobacco consumption is a global burden, particularly in Asian countries, we recommend that the Parties to the FGTC adopt continuous monitoring of the implementation of taxation policy for smokeless tobacco control. Taxation on all kinds of tobacco products, without any exceptions, should be considered as the need of the hour. Smokeless tobacco products can also be categorized separately and taxed differently under state tobacco tax codes.

\section{CONCLUSIONS}

There is a disparity in tobacco taxation among FGTC Parties and the parity differs based on the economic status and WHO region of the countries. Also, smokeless tobacco products were highly undertaxed compared to cigarettes. Hence, tobacco control advocates should continue to support the imposition of higher tobacco taxes. They should also promote tobacco tax equity, to ensure that smokeless tobacco products are taxed at the same rate as cigarettes. We also recommend that countries that are already taxing tobacco products at $70 \%$ should further increase the rate over time, taking into account inflation and income changes, to ensure that tobacco products become progressively less affordable.

\section{REFERENCES}

1. Warren CW, Jones NR, Eriksen MP, Asma S, Global Tobacco Surveillance System (GTSS) collaborative group. Patterns of global tobacco use in young people and implications for future chronic disease burden in adults. The Lancet. 2006;367(9512):749-753. doi:10.1016/S0140-6736(06)68192-0

2. Ekpu VU, Brown AK. The economic impact of smoking and of reducing smoking prevalence: review of evidence. Tob Use Insights. 2015;8:1-35. doi:10.4137/TUI.S15628

3. Mehrotra R, Yadav A, Sinha DN, et al. Smokeless tobacco control in 180 countries across the globe: call to action for full implementation of WHO FCTC measures. Lancet Oncol. 2019;20(4):e208-e217. doi:10.1016/S1470-2045(19)30084-1

4. Shang C, Yadav A, Stoklosa M, Kontsevaya A, Lewis FB, Pana A, Reyes I. Country-specific costs of implementing the WHO FCTC tobacco control policies and potential financing sources. PloS one. 2018;13(10):e0204903. doi:10.1371/journal.pone.0204903

5. Jha P, Chaloupka FJ. Tobacco control in developing countries. Oxford, United Kingdom: Oxford University Press; 2000.

6. Chaloupka FJ, Hu TW, Warner KE, Jacobs R, Yurekli A. The taxation of tobacco products. In: Jha P, Chaloupka F, eds. Tobacco Control in Developing Countries. Oxford, United Kingdom: Oxford University Press; 2000.

7. World Health Organization. Taxation and the Economics of Tobacco Control. In: Gender, Women, and the Tobacco Epidemic. https://www.who.int/tobacco/publications/ gender/en_tfi_gender_women_taxation_economic_ tobacco_control.pdf?ua=1. Accessed July 26, 2020.

8. Jacobs R, Gale HF, Capehart TC, Zhang P, Jha P. The supply-side effects of tobacco control policies. Oxford, United Kingdom: Oxford University Press; 2000.

9. Sinha DN, Palipudi KM, Jones CK, et al. Levels and trends of smokeless tobacco use among youth in countries of the World Health Organization South-East Asia Region. Indian J Cancer. 2014;51(Suppl 1):S50-S53. doi:10.4103/0019-509X.14747

10. World Health Organization. WHO report on the global tobacco epidemic, 2017: monitoring tobacco use and prevention policies. Geneva, Switzerland: World Health Organization; 2017. https://www.who.int/tobacco/ global_report/2017/en/. Accessed July 26, 2020.

11. World Health Organization. WHO report on the global tobacco epidemic 2019: Offer help to quit tobacco use. Geneva, Switzerland: World Health Organization; 2019. https://www.who.int/teams/health-promotion/tobaccocontrol/who-report-on-the-global-tobacco-epidemic2019\#: :text=The $\% 20 \% 22$ WHO $\% 20$ report $\% 20$ on $\% 20$ the,bans $\% 20$ to $\% 20$ no\%20smoking\%20areas.. Accessed July 26, 2020.

12. Delnevo CD, Wackowski OA, Giovenco DP, Manderski MT, Hrywna M, Ling PM. Examining market trends in the United States smokeless tobacco use: 2005-2011. Tob Control. 2014;23(2):107-112. doi:10.1136/tobaccocontrol-2012-050739

13. Bayly M, Scollo MM, Wakefield MA. Who uses rollies? Trends in product offerings, price and use of roll-your- 
own tobacco in Australia. Tob Control. 2019;28(3):317324. doi:10.1136/tobaccocontrol-2018-054334

14. Sinha DN, Rizwan SA, Aryal KK, Karki KB, Zaman MM, Gupta PC. Trends of smokeless tobacco use among adults (aged 15-49 years) in Bangladesh, India and Nepal. Asian Pac J Cancer Prev. 2015;16(15):6561-6568. doi:10.7314/APJCP.2015.16.15.6561

15. Nargis N, Stoklosa M, Drope J, et al. Trend in the affordability of tobacco products in Bangladesh: findings from the ITC Bangladesh Surveys. Tob Control. 2019;28(Suppl 1):s20-s30. doi:10.1136/tobaccocontrol-2017-054035

16. Branston JR, McNeill A, Gilmore AB, Hiscock R, Partos TR. Keeping smoking affordable in higher tax environments via smoking thinner roll-your-own cigarettes: Findings from the International Tobacco Control Four Country Survey 2006-15. Drug Alcohol Depend. 2018;193:110116. doi:10.1016/j.drugalcdep.2018.07.047

17. World Health Organization. WHO report on the global tobacco epidemic 2015: raising taxes on tobacco. Geneva, Switzerland: World Health Organization; 2015. https:// apps.who.int/iris/bitstream/handle/10665/178577/ WHO_NMH_PND_15.5_eng.pdf; jsessionid= 6BB4DA8DD548231CA1268532A9927153? sequence $=1$. Accessed July 26, 2020.

18. National Center for Chronic Disease Prevention and Health Promotion (US) Office on Smoking and Health. Preventing Tobacco Use Among Youth and Young Adults: A Report of the Surgeon General. Atlanta, GA: Centers for Disease Control and Prevention (US); 2012. https:// www.ncbi.nlm.nih.gov/books/NBK99238/. Accessed July 25, 2020.

19. Prante G. What Is Proper Tax Policy for Smokeless Tobacco Products? https://taxfoundation.org/whatproper-tax-policy-smokeless-tobacco-products-0/. Published March 26, 2008. Accessed July 25, 2020.

20. World Health Organization. Guidelines for Implementation of Article 6 of the WHO FCTC: Price and tax measures to reduce demand for tobacco. Geneva, Switzerland: World Health Organization; 2014. https://www.who.int/fctc/ guidelines/adopted/Guidelines_article_6.pdf. Accessed July 26, 2020.
CONFLICTS OF INTEREST

The authors have completed and submitted the ICMJE Form for Disclosure of Potential Conflicts of Interest and none was reported.

FUNDING

There was no source of funding for this research.

PROVENANCE AND PEER REVIEW

Not commissioned; externally peer reviewed. 